\title{
Comprehensive study of 226-1000 hz multifrequency tympanometry measures in infants
}

\begin{abstract}
Objective: In this report, we aimed to compare the results and clinical performance of the $226-1000 \mathrm{~Hz}$ multifrequency tympanometry measurements.

Materials and Methods: 0-1years old 85 babies who had admitted to our otorhinolaryngology clinic were included to the study. After the clinical evaluation of the patients, all tympanometric measurements were done by an audiologist, and the results were classified and compared according to age groups.

Results: In this study, $1000 \mathrm{~Hz}$ tympanometry measurements are more sensitive than the $226 \mathrm{~Hz}$ tympanometry measurements to discriminate the middle ear effusions. Particularly, $1000 \mathrm{~Hz}$ tympanometry measurements are more significant on 0-6month's group.

Conclusion: Tympanometry measurements are reliable methods with clinical evaluation to discriminate the middle ear effusions on $0-1$ age infants. Success rate of the $1000 \mathrm{~Hz}$ tympanometry measurements is better than $226 \mathrm{~Hz}$ measurements to identify the middle ear effusions on this age group.
\end{abstract}

Volume 2 Issue 4 - 2015

\author{
Ahmet Mutlu,' Merve Durgut, ${ }^{2}$ Murat \\ Ozturk,' Mustafa Çağlar Buday,' Murat \\ Topdag,' Mete İșeri' \\ 'Department of Otolaryngology, Kocaeli University Faculty of \\ Medicine, Turkey \\ ${ }^{2}$ Department of Audiology, Kocaeli University Faculty of \\ Medicine, Turkey
}

\begin{abstract}
Correspondence: Murat Ozturk, Department of Otolaryngology, Kocaeli University Faculty of Medicine, KBB Anabilim Dali, 4I 380, Kocaeli, Turkey, Tel +90 532 5902634, Fax
\end{abstract} +90 262 3037003, Email muratkbb@gmail.com

Received: April 07, 2015 | Published: April 15, 2015

Keywords: tympanometry, middle ear effusion, hearing loss

\section{Introduction}

Loss of hearing that occurs at an early age reduces language development, learning skills, and psychosocial development of a child. The newborn hearing screening programs was enacted to detect and correct this situation, and to support their psychosocial development. The middle ear effusion (MEE) causes errors in these newborn hearing screening tests. Otitis media is a pervasive childhood disease posing significant healthcare challenges. Greater Boston studies have shown that $70 \%$ of children have at least one episode of acute otitis media attack before 2 years of age. ${ }^{1}$ Lee's study has shown that, otomicroscopy is most successful method in evaluation of the middle ear effusion in child group. ${ }^{2}$ Multi-frequency tympanometry provides more accurate and detailed information about the middle ear dynamics than standard tympanometry. It is based on the analysis of tympanograms at a wide range of frequencies between 226 and $1,000 \mathrm{~Hz}$. Multifrequency measures have been used to more completely describe the tympanometric differences seen in the neonate in comparison to the older child. This technique allows the assessment of the relative contribution of mass, stiffness, and resistive elements to acoustic admittance of sound by employing multiple probe tone frequencies.

Many clinical studies use of higher-frequency probe tones has been recommended when testing young infants, because higher frequency tones appear to be more sensitive to middle ear effusion..$^{3-6}$ In this study, we aimed to compare the results and clinical performance of the $226-1000 \mathrm{~Hz}$ multifrequency tympanometry measurements in babies under 1year old.

\section{Materials and methods}

Eighty-five babies less than 1year old who applied to Kocaeli University Medical Faculty Otorhinolaryngology Department between years 2012-2013 were the subjects of this study. The average days of age was 121 days ranging 11 to 362 days. Their otoscopic and otomicroscopic examinations were done by otorhinolaryngology specialist. The children who has outer ear and tympanum anomaly or who are in monitor because of uraniscochasma or cleft lip or who are proved or suspected syndromic diseases, are kept out of study. After taking the approval of the babies' (who are in the appropriate age group) parents, evaluations with their usual probe tone $(226 \mathrm{~Hz})$ and high frequency $(1000 \mathrm{~Hz})$ probe tone are done with the multifrequency tympanometry tool (Interacoustics ${ }^{\circledR}$ AT235h, Assens, Denmark), and acquired trace shapes and numeric data has been saved. Tympanometry evaluations are classified according to tympanogram classification of Jerger that is summarized below.

Tympanogram Values Classification (Jerger classification 1970):

Type A: Compliance: 0.3 to $1.6 \mathrm{mmho}$ and pressure: from -100 to +100daPa.

Type As: Compliance: 0.15 to $0.3 \mathrm{mmho}$ and pressure: from -100 to +100daPa.

Type Ad: Compliance: $>1.6 \mathrm{mmho}$ and pressure: -100 to $+100 \mathrm{daPa}$.

Type B: Compliance: none detectable and pressure: none detectable.

Type C: Compliance: 0.3 to $1.6 \mathrm{mmho}$ and pressure: $<-100 \mathrm{daPa}$.

Type A tympanogram traces was considered healthy, and other tympanogram traces (Type As, Ad, B, C) have been assessed under the abnormal or unhealthy group according to the Jerger's classification. Data were evaluated in three groups according to the age of the babies; 0-180days, 181-365days, and all. Normal and abnormal data (normal and sick patients) distribution, average compliance values, and peak pressure values were analyzed with SPSS version 13.0, Chicago, IL, USA. The results are interpreted with the appropriate statistical test, $\mathrm{p}<0.05$ was considered statistically significant. This study is approved by the Kocaeli University Clinical Research Ethics Committee (Protocol Code: 2012/74), and supported by the Kocaeli University Scientific Research Project Unit in scope of research project. 


\section{Results}

Eighty-five babies (42 boys and 43 girls) aged between 10 362days were included. 170 measurements were made including the left and right ears. While $226 \mathrm{~Hz}$ tympanometry evaluated 101 ears as normal, and 69ears as sick; $1000 \mathrm{~Hz}$ tympanometry evaluated 54ears as normal, and 116ears as sick (Table 1). Distribution rates compared with McNemar test for dependent groups $(p=0,000)$ have shown that $1000 \mathrm{~Hz}$ tympanometry determines healthy and sick ears more sensitive than $226 \mathrm{~Hz}$ tympanometry. When the same data classified according to the age groups, in the 0-180days group $226 \mathrm{~Hz}$ tympanometry measured 93ears as healthy, 50ears as sick; $1000 \mathrm{~Hz}$ tympanometry measured 48years as healthy, 95ears as sick (Table 2). When distribution percentages compared with McNamer dependent groups test, $1000 \mathrm{~Hz}$ tympanogram was found more sensitive than $226 \mathrm{~Hz}$ tympanogram at determining healthy and sick ears in 0-180days group. In the group of 181-365 days babies, $226 \mathrm{~Hz}$ tympanometry evaluated 8 ears as healthy, and 19 ears as sick; $1000 \mathrm{~Hz}$ tympanometry evaluated 6ears as healthy, and 21 ears as sick (Table 3 ). Though the universe was smaller than the previous group, it was considered sufficient for the statistical evaluation and $p=0.774$ was found. According to this result in 181-365 days population, $1000 \mathrm{~Hz}$ tympanometry is not more successful than $226 \mathrm{~Hz}$ tympanometry statistically in determining healthy and sick ears. Average compliance value of $226 \mathrm{~Hz}$ and $1000 \mathrm{~Hz}$ measurements were compared using the Wilcoxon test. Non-parametric tests were used due to lack of a homogeneous distribution of the measured values. Average compliance values of all population were evaluated, and statistically significant difference hasn't observed between the 226 and $1000 \mathrm{~Hz}$ tympanometry measurements $(\mathrm{p}>0,05)$. When 0 -180days and 181365 days are compared, statistically significant differences were observed between the groups $(\mathrm{p}<0,05)$.

Pick pressure levels of the $226 \mathrm{~Hz}-1000 \mathrm{~Hz}$ tympanometry measurements were compared with Wilcoxon test, and obtained results of the general population, 0-180 day and 181-365 day groups are statistically significant $(\mathrm{p}<0,05)$. Peak pressure levels and compliance results of the $226-1000 \mathrm{~Hz}$ measurements except type B were compared. Compliance levels were statistically significant in general population, 0-180days and 181-365days group, otherwise peak pressure levels didn't display the statistical significance.

Table I $226 \mathrm{~Hz}$ and $1000 \mathrm{~Hz}$ tympanometry measurements grouped as normal (Type A trace) and sick (Type Ad, As, B, C traces) in all population, (McNemar test results $(p)=0,000 ; p<0,05)(\mathrm{Hz}$ : Hertz).

\begin{tabular}{|c|c|c|c|c|c|}
\hline & & & \multicolumn{3}{|c|}{ I 000 Hz Tympanogram } \\
\hline & & & Normal & Sick & Total \\
\hline & Normal & Number & 31 & 70 & 101 \\
\hline & & $\%$ in $226 \mathrm{~Hz}$ Tympanogram & 30,7 & 69,3 & 100 \\
\hline & & $\%$ in $1000 \mathrm{~Hz}$ Tympanogram & 57,4 & 60,3 & 59,4 \\
\hline $226 \mathrm{~Hz}$ & Sick & Number & 23 & 46 & 69 \\
\hline \multirow{5}{*}{ Tympanogram } & & $\%$ in $226 \mathrm{~Hz}$ Tympanogram & 33,3 & 66,7 & 100 \\
\hline & & $\%$ in $1000 \mathrm{~Hz}$ Tympanogram & 42,6 & 39,7 & 40,6 \\
\hline & Total & Number & 54 & 116 & 170 \\
\hline & & $\%$ in $226 \mathrm{~Hz}$ Tympanogram & 31,8 & 68,2 & 100 \\
\hline & & $\%$ in $1000 \mathrm{~Hz}$ Tympanogram & 100 & 100 & 100 \\
\hline
\end{tabular}

Table $2226 \mathrm{~Hz}$ and $1000 \mathrm{~Hz}$ tympanometry measurements grouped as normal (Type A trace) and sick (Type Ad, As, B, C traces) in 0-I80 days population, $($ McNemar test results $(p)=0,000 ; p<0,05)(\mathrm{Hz}$ : Hertz).

\begin{tabular}{|c|c|c|c|c|c|}
\hline & & & \multicolumn{3}{|c|}{ I 000 Hz Tympanogram } \\
\hline & & & Normal & Sick & Total \\
\hline \multirow{9}{*}{$\begin{array}{c}226 \mathrm{~Hz} \\
\text { Tympanogram }\end{array}$} & Normal & Number & 30 & 63 & 93 \\
\hline & & $\%$ in $226 \mathrm{~Hz}$ Tympanogram & 32,3 & 67,7 & 100 \\
\hline & & $\%$ in $1000 \mathrm{~Hz}$ Tympanogram & 62,5 & 66,3 & 65 \\
\hline & Sick & Number & 18 & 32 & 50 \\
\hline & & $\%$ in $226 \mathrm{~Hz}$ Tympanogram & 36 & 64 & 100 \\
\hline & & $\%$ in $1000 \mathrm{~Hz}$ Tympanogram & 37,5 & 33,7 & 35 \\
\hline & Total & Number & 48 & 95 & 143 \\
\hline & & $\%$ in $226 \mathrm{~Hz}$ Tympanogram & 33,6 & 66,4 & 100 \\
\hline & & $\%$ in $1000 \mathrm{~Hz}$ Tympanogram & 100 & 100 & 100 \\
\hline
\end{tabular}


Table $3226 \mathrm{~Hz}$ and $1000 \mathrm{~Hz}$ tympanometry measurements grouped as normal (Type A trace) and sick (Type Ad, As, B, C traces) in I8I-365days population, $($ McNemar test results $(p)=0,774 ; p>0,05)(H z:$ Hertz $)$

\begin{tabular}{|c|c|c|c|c|c|}
\hline & & & $1000 \mathrm{~Hz} 7$ & ogram & \\
\hline & & & Normal & Sick & Total \\
\hline & Normal & Number & I & 7 & 8 \\
\hline & & $\%$ in $226 \mathrm{~Hz}$ Tympanogram & 12,5 & 87,5 & 100 \\
\hline & & $\%$ in $1000 \mathrm{~Hz}$ Tympanogram & 16,7 & 33,3 & 29,6 \\
\hline $226 \mathrm{~Hz}$ & Sick & Number & 5 & 14 & 19 \\
\hline Tympanogram & & $\%$ in $226 \mathrm{~Hz}$ Tympanogram & 26,3 & 73,7 & 100 \\
\hline & & $\%$ in $1000 \mathrm{~Hz}$ Tympanogram & 83,3 & 66,7 & 70,4 \\
\hline & Total & Number & 6 & 21 & 27 \\
\hline & & $\%$ in $226 \mathrm{~Hz}$ Tympanogram & 22,2 & 77,8 & 100 \\
\hline & & $\%$ in $1000 \mathrm{~Hz}$ Tympanogram & 100 & 100 & 100 \\
\hline
\end{tabular}

\section{Discussion}

Nowadays, early identification of the infants hearing impairment is important. Studies have shown that children identified with hearing loss prior to 6months of age have a better chance of developing skills equivalent to their peers. For this recommend, infant hearing screening programs are widely accepted. Middle ear effusions are the most common reason of the hearing loss; therefore tympanometry measurements become more noteworthy on certain diagnosis and treatment screening.

Narrow external ear canal and immature cartilage structure of the pinna decline the transduced sound level to the tympanic membrane and middle ear system. Different tissue types show specific resistance levels to each frequency as a result of this issue sound transmission levels vary. Furthermore, mass of the middle ear structures and stiffness effect of the bony system determine the sound compliancy. Mass of the tympanic membrane, bony components (malleus, incus, stapes) define the mass reactions. Tympanic membrane flexibility, bone transmission mechanism and perilymphatic fluid strain to the stapes footplate determine the stiffness element. In considering the anatomical and physiological conditions, adult middle ear defined as a stiffness-controlled system at low frequencies and infant middle ear system is a mass-dominated system. Due to the this middle ear resonant hypothesis, recent studies showed multi-frequency tympanometry measurements have a better success rate than classic tympanometry measurements on revealing the middle ear effusions in infants. ${ }^{7-9}$ Zhigi et al., ${ }^{10}$ compared $226 \mathrm{~Hz}-1000 \mathrm{~Hz}$ tympanometry measurements with spiral temporal bone computerized tomography on 0-6 months infants. $1000 \mathrm{~Hz}$ tympanometry measurements identify presence middle ear effusions with a similar concordance on computerized tomography; furthermore $1000 \mathrm{~Hz}$ tympanometry measurements are more successful than $226 \mathrm{~Hz}$ tympanometry measurements. On the other hand; considering potential cancer risk, which is related to the radiation dosage of the spiral computerized tomography, physicians have to pay attention on physical examination for the certain diagnosis. Although, suboptimal physical examination of the infants; tympanometry measurements help to diagnose the middle ear effusions and are preferred by physicians.
The age group distribution of this present study is between 0 and 180days (first six months). Based on hearing screening programs, hearing loss is expected to be diagnosed during the first six months. The application of conventional hearing aids for rehabilitation of the detected hearing loss usually occurs between 181 and 365days (6-12months).

Different compliance or transmission values are expected to be present in tympanometric measurements since different audio frequencies are used. In our study, when the mean compliance measurement values were compared with the general study group and different age groups, statistically significant differences were found between $1,000 \mathrm{~Hz}$ tympanometry and $226 \mathrm{~Hz}$ tympanometry. Mean values of the compliance distributions differences based on the age groups of the babies were found to be significantly different at 226 and $1,000 \mathrm{~Hz}$; and increased at $1,000 \mathrm{~Hz}$, except in babies with tympanogram type B or in other words babies suspicious of having otitis media with effusion (OME) present. This suggests that the test measures that the compliance values are better at $1,000 \mathrm{~Hz}$ and that it could be significant in detecting other middle ear pathologies.

Mean pressure values in high frequency tympanometry were statistically significant compared to low frequency tympanometry. The pressure of development of tympanogram trajectory peak point was compared between the general study group and age groups. This difference may be due to the variability in the pressure values in the patients and that $1,000 \mathrm{~Hz}$ can more easily detect Type B compared to $226 \mathrm{~Hz}$. A real pressure measurement cannot be done because either a peak tympanometry point is absent in OME or due to a straight tympanometry trajectory. When the mean pressures in the babies with tympanogram values were other than Type $\mathrm{B}$, no significantly different values were obtained between $226 \mathrm{~Hz}$ and $1,000 \mathrm{~Hz}$ tympanograms. With these results, it can be suggested that $226 \mathrm{~Hz}$ and $1,000 \mathrm{~Hz}$ produce similar results in detecting peak point pressure values in patients other than tympanogram Type B. Both hertz frequencies seem to be useful in detection and follow-up of the Type $\mathrm{C}$ group in which pressure values are the primary concern.

When this present study groups patient and healthy baby 
populations, $1,000 \mathrm{~Hz}$ tympanometry was found to be more accurate and more sensitive to the differentiation between patient and healthy individuals in all age groups and in both 0-180days and 181-365days old babies compared to $226 \mathrm{~Hz}$ tympanometry. These findings were found to be compatible with the current literature findings. ${ }^{810}$ The external ear and mastoid bone become harder as the baby grows, which may account for the more accurate compliance measurement in higher frequencies.

In conclusion, this study demonstrates that $1,000 \mathrm{~Hz}$ tympanometry detects more accurately for the diagnosis and treatment of OME with variable pressure differences and compliance values in the baby population of first six months of life compared to $226 \mathrm{~Hz}$ tympanometry. $1,000 \mathrm{~Hz}$ can also be considered as a more sensitive in detecting the compliance values in these age groups and in differentiating the lowest and highest compliance values. Advanced and controlled clinical research is needed in the evaluation of other middle ear pathologies except OME.

\section{Financial Support}

This study is supported by the Kocaeli University Scientific Research Project Unit in scope of research project.

This study has been published as a presentation at the 36th national ENT congress in Antalya, Turkey.

\section{Acknowledgments}

None.

\section{Conflicts of interest}

The authors declare that there is no conflicts of interest.

\section{References}

1. Teele DW, Klein JO, Rosner B. Epidemiology of otitis media during the first seven years of life in children in greater Boston: a prospective, cohort study. J Infect Dis. 1989;160(1):83-94.

2. Lee DH. How to improve the accuracy of diagnosing otitis media with effusion in a pediatric population. Int $J$ Pediatr Otorhinolaryngol. 2010;74(2):151-153.

3. Holte L, Margolis RH, Cavanaugh RM. Developmental changes in multifrequency tympanograms. Audiology. 1991;30(1):1-24.

4. Hunter LL, Margolis RH. Multifrequency tympanometry: current clinical application. Am J Audiol. 1992;1:33-43.

5. McKinley AM, Grose JH, Roush J. Multi frequency tympanometry and evoked acoustic emissions in neonates during the first 24 hours of life. $J$ Am Acad Audiol. 1997;8(3):218-223.

6. Jerger J. Clinical experience with impedance audiometry. Arch Otolaryngol. 1970;92(4):311-324.

7. Hoffmann A, Deuster D, Rosslau K, et al. Feasibility of $1000 \mathrm{~Hz}$ tympanometry in infants: Tympanometric trace classification and choice of probe tone in relation to age. Int J Pediatr Otorhinolaryngol. 2013;77(7):1198-1203.

8. Lewis MP, Bell EB, Evans AK. A comparison of tympanometry with $226 \mathrm{~Hz}$ and $1000 \mathrm{~Hz}$ probe tones in children with Down syndrome. Int $J$ Pediatr Otorhinolaryngol. 2011;75(12):1492-1495.

9. Son EJ, Park YA, Kim JH, et al. Classification of trace patterns of 226and $1000-\mathrm{Hz}$ tympanometry in healthy neonates. Auris Nasus Larynx. 2012;39(5):455-460.

10. Zhiqi L, Kun Y, Zhiwu H. Tympanometry in infants with middle ear effusion having been identified using spiral computerized tomography. Am J Otolaryngol. 2010;31(2);96-103. 